Preprints of the

Max Planck Institute for

Research on Collective Goods

Bonn 2008/7

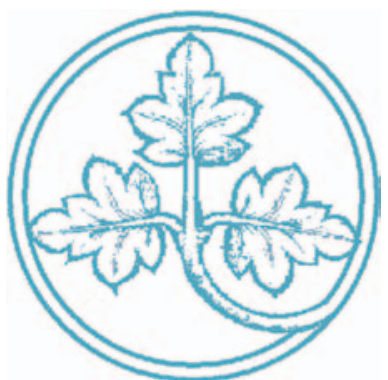

International Organizations as Corporate Actors: Agency and Emergence in Theories of International Relations

Remi Maier-Rigaud

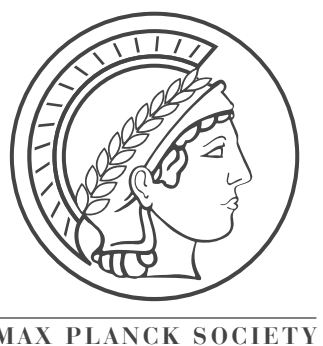




\section{International Organizations as Corporate Actors: Agency and Emergence in Theories of International Relations}

Remi Maier-Rigaud

February 2008 


\title{
International Organizations as Corporate Actors: Agency and Emergence in Theories of International Relations
}

\author{
Remi Maier-Rigaud ${ }^{1}$
}

Introduction

I. Reductionist theories of international organizations 4

1. Neorealism 4

2. Rational choice institutionalism 10

II. Foundations for a conceptualization of emergent international organizations 17

$\begin{array}{ll}\text { 1. Symbolic interactionism } & 17\end{array}$

2. Social constructivism: inter-state practice matters 18

III. Emergence, autonomy and power of international organizations 21

1. International organizations as emergent high-order corporate actors 21

2. Knowledge generation and the productive power of discourses 25

$\begin{array}{lr}\text { Conclusion } & 29\end{array}$

References $\quad 30$

1 This chapter has benefited from many discussions within the Corporate Actors Group at the Max Planck Institute for Research on Collective Goods. I want to thank Martin Beckenkamp, Julia Ellinger, Christoph Engel, Stefanie Brilon, Frank Maier-Rigaud, Andreas Nicklisch, Tobias Salz and Anne van Aken, for their helpful comments. I am also indebted to Brian Cooper for his linguistic assistance. Last but not least, I want to thank Alkuin Koelliker, who not just commented on this chapter several times in a very helpful way, but who discussed this project and provided important input from the start to the finalization of this chapter. 


\section{Introduction}

Since the end of World War II, international organizations have increasingly gained in importance for inter-state cooperation and international politics. Whereas some international organizations seem to function solely as fora for the coordination of state actor interests, others seem to have emerged as actors of their own. In order to discuss this observation, two questions will be raised.

First, are international organizations unitary actors? Like treaties between states (e.g., free trade agreements) and regional integration arrangements, international organizations are a subcategory of international institutions. ${ }^{2}$ International institutions are a "set of rules meant to govern international behaviour" (Simmons/Martin 2002: 194). This definition is based on the broader definition of institutions as rules of the game in social life by Douglass North: "Institutions are [...] the humanly devised constraints that shape human interaction” (North 1990: 3). International organizations are a physical entity with a bureaucratic structure that embodies a set of rules. The other sub-categories of institutions are often contained in international organizations, implying a more qualified type of institution. Therefore, international organizations are the most differentiated type of international institution. This is reflected in the fact that most international organizations ${ }^{3}$ are accorded legal personality in international law. ${ }^{4}$

However, not all international organizations are corporate actors and the state of legal personality does not automatically make an international organization a corporate actor. Rather, a corporate actor ${ }^{5}$ is composed of parts or members, but its behavior is not decomposable or reducible to its parts. This necessary and sufficient feature of corporate actors is called 'emergence' and accounts for the autonomy of corporate actors. The process of emergence has been described by Flam (1990: 5) as driven by the capacity of "member-created organizations [...] to transform themselves from a 'mere' set of formal organizational rules into corporate actors, endowed with a capacity to act, and acting independently from the intentions and interests of their creators". Applied to international organizations, this means that they are corporate actors, if their behavior and actions cannot be reduced to the micro level. In order to be corporate actors, international organizations have to show some kind of autonomy vis-à-vis their member-states. They have to

2 These sub-categories are not necessarily mutually exclusive since one can imagine an arrangement that encompasses all three sub-categories.

3 According to the common definition in international law, an international organization has to exhibit four features: It should be a permanent association of two or more states based on a founding treaty and the organization should be independently in charge of its own tasks, which implies the presence of at least one body entitled to act. Cf. for example Peters (2006: 169). One should be aware that this definition of international law is not identical to the emerging autonomy which defines corporate actors (see below).

4 The state of legal personality is either explicit or implicit. Explicit means that the founding treaty or constitution of an organization refers to its legal personality. For example, the International Labour Organisation possesses full legal personality, in particular the capacity to contract, acquire property and to institute legal proceedings (cf. Constitution of the International Labour Organisation: Chapter IV, Article 39). If the state of an organization is not made explicit in its founding documents, then it can also be deduced from these documents. Therefore, it is necessary that the functions and tasks of an organization laid down in these documents require it to possess legal personality. In the Bernadotte case, the International Court of Justice accorded to the UN legal personality due to the competencies and powers implied in the UN Charter (cf. Peters 2006). Corporate actors may take various forms, as for example sports clubs, political parties, firms or states. 
exhibit a genuine quality that makes them more than the sum of their parts. This autonomy becomes visible in the ability of international organizations to alter the identities and interests of its members through a feedback mechanism. ${ }^{6}$

Second, to what extent are international organizations corporate actors, based on the autonomy criterion? In order to address the quality of international organizations as corporate actors, political science literature may be instructive. This chapter aims at inquiring into the three principal schools of international relations theory: neorealism, rational choice institutionalism ${ }^{7}$ and social constructivism. ${ }^{8}$ What are their implicit or explicit conceptions vis-à-vis international organizations $?^{9}$ To what degree do they sustain the corporate actors approach?

The first and the second part of this chapter give an overview of existing theories of international relations and how they conceptualize international organizations. For readers who are familiar with international relations theory, these sections will not provide something entirely new, but for those coming from other disciplines this will give a short introduction to the state of the debate in this field. In the first part, neorealism and rational choice institutionalism are compared. Analytically, both theories can be attributed to an economic approach to international organizations, which emphasizes the agency of states and, therefore, tends to view international organizations as mere instruments of state interests. This is contrasted with social constructivism, a sociological approach presented in the second part, which allows a conceptualization of international organizations as emergent phenomena. ${ }^{10}$ Social constructivism enables a view of international organizations as autonomous actors, due to its roots in symbolic interactionism.

The third part of this chapter attempts to combine different social constructivist lines of thoughts in order to obtain a theoretical synthesis of social constructivist accounts of international organi-

6 In addition to the criterion of autonomy, corporate actors can be defined as exhibiting a bureaucratic structure. This would delineate corporate actors from emergent "collective actors", which do not require an institutional (bureaucratic) structure. Accordingly, "collective actor” is a more general category that includes corporate actors as a sub-category, since the latter are necessarily associated with an internal institutional structure. In turn, the “international regime” (Krasner 1995, Hasenclever/Mayer/Rittberger 1997) concept can be subsumed as a form of collective action. Regimes lack the bureaucratic structure of international organizations but have formal elements that delineate regimes from the third type of international institutions, namely the more informal practices of international relations such as state sovereignty and diplomatic immunity (cf. Hansen 1996: 23).

7 Throughout this chapter, the term "rational choice institutionalism" is used to describe a school of thought in international relations where institutions are created in order to solve collective action problems in the first place. It is broadly synonymous to "neoliberal institutionalism”, "neoinstitutionalism” or "rational functionalism”.

8 A multitude of theories of international relations exists today, which have mainly evolved from the debate between realists and idealists. This debate has contributed to the emergence of many different schools and to a proliferation of the prefix "neo" to describe which broad tradition a theory is located in while it is new at the same time. These theoretical differentiations have resulted in a jungle of theories, making it increasingly difficult to keep a clear picture of what is going on in all strands of international relations theory.

9 Strikingly, a genuine theory of international organizations does not exist. Instead, the theoretical conception of international organizations is more or less implicit in the different theories of international relations. The fact that these theories deal with the interaction of states in the first place already casts some light on the predominant conception of international organizations as 'outcomes' rather than 'actors'. For exceptions, see II and III.

10 The analytic distinction between economic and sociological approaches to international organizations is taken from Barnett/Finnemore (1999: 702-706). 
zations as autonomous, knowledge-generating corporate actors. In the first section, "emergence” with respect to international organizations as high-order corporate actors is defined. Then three types of interaction between states and international organizations are presented, in order to clarify what the emergent case and its processes are. In the second section, it is explored how international organizations acquire autonomy through the production and diffusion of knowledge. On this basis, some tentative conclusions are drawn regarding the power of governance forms embodied by international organizations.

\section{Reductionist theories of international organizations}

\section{Neorealism}

Classic realism is most prominently associated with the works of Hans Morgenthau who assumed that human nature is 'bad' in the sense that states exhibit a 'will to power' and that, accordingly, states find themselves in a Hobbesian situation of mutual threat. ${ }^{11}$ In contrast, neorealists make no argument about human nature but seek systemic properties that account for the situation of mutual threat (anarchy), in which states strive for security.

\section{The international system: anarchy and no functional differentiation}

This makes neorealism a systemic theory. ${ }^{12}$ It starts from the assumption that the international system is anarchic and states thus strive for security through their reliance on self-help instead of cooperation. The strict separation between the structure and the units of the international system is essential for the neorealist argument. The units in the analysis of Waltz are the nation-states which in his view are basically the only relevant actors in the international system.

According to Waltz (1979: 80), "structure is defined by the arrangements of its parts." 'Arrangement' in the sense used by Waltz refers to the relative distribution of power among states. His definition excludes everything that can be ascribed to the units: motives, qualities and even the interaction between states. The structure of the international system is an invisible but relevant abstraction, like grammar for the use of language. Waltz further shows what distinguishes the structure of the international system from domestic political structure. Three properties of domestic structure are emphasized:

a) Domestic politics are hierarchically ordered, i.e., institutions etc. are in "relations of superand subordination” (Waltz 1979: 81).

b) The domestic political structure is characterized by a formal and functional differentiation of its units.

11 Classic realism is used here in a general sense including all realist thinkers from Thucydides and Machiavelli to Morgenthau. It is anti-moral in the sense that it has been born out of an "opposition to moral idealism" (Forde 1995: 143). This originally normative notion of realism has been intentionally abandoned by neorealist thinkers in order to fulfil the criteria of a scientific theory in positivistic terms (cf. Forde 1995).

12 Therefore, it is often also called 'structural realism'. Kenneth Waltz developed this theory in his influential monograph “Theory of International Politics” (1979). See also: Waltz (2000). 
c) The domestic political structure is characterized by the specific "distribution of capabilities across those units" (Waltz 1979: 81).

By contrast, for the structure of the international system only the characterization c applies: it is characterized by the distribution of capabilities between states. An order (characterization a) is absent from the international system, since there is no governance structure and anarchy prevails. This is mainly due to the lack of functional differentiation (Waltz 1979: 144).

In the international system, states perform similar tasks; they are like units in the sense that they are politically autonomous and sovereign. This implies that each state "duplicates the activities of other states" (Waltz 1979: 96). Because states perform similar functions, they do not complement each other. Instead, the relations between states are characterized by competition, in contrast to the relations within one state, where internally different parts perform functions that are complementary to each other (characterization b).

Since Waltz attributes actions and processes to the states, he reaches a strict analytical separation of units and processes, on the one hand, and structures and positions, on the other. This distinction is an important necessary condition for his theory to explain how structure, and especially the position of functionally identical units vis-à-vis each other, influences processes and actions of states/units. His argument amounts to the claim that the structure of the international system induces competition as the main mechanism that drives state action. ${ }^{13}$

State action is therefore a dependent rather than an independent variable, because it derives from the situation a state finds itself in - i.e., the distribution of power in the international system. ${ }^{14}$ The distribution of power defined through the distribution of accumulated state capacities is the explanatory variable in the neorealist setting. Therefore, neorealism exhibits a materialist ontology. ${ }^{15}$ This and the anarchic (competitive) structure of the international system explain the focus of state action on relative gains/positionality. ${ }^{16}$ The systemic element lies in the fact that a single state cannot resist this logic of competition without putting its existence at risk. The structure constitutes a set of constraints for the behavior of (rational) units. The assumption made by Waltz that states seek to ensure their own survival does not have to be met by all states. For the

13 With the breakdown of the Soviet Union, many scholars of international relations considered neorealism to be outdated and no longer sufficient to explain international relations in the post cold war era. In a defence of his theory, Waltz (2000) emphasizes that the anarchic structure of the international system still prevails; leaving states no other choice but to strive for security on their own. According to him, changes associated with the breakdown of bipolarity occurred at the unit (state) level, not at the structural level.

14 This has been criticized by Gourevitch (1978), who argues that domestic structures cannot be fully explained by the international system, and vice versa. In his view, the international system is "underdetermining" (Gourevitch 1978: 900), always leaving some decision leeway that requires an explanation on the domestic level.

15 This has been extensively described by Wendt (1999), who turns this neorealist assumption upside down in his "Social Theory of International Relations".

16 Unlike in economics, Waltz (1979: 134-138) points out that competition is not desirable in the international system if the survival of states is assumed as a goal. Small, oligopolistic structures are thus favored over the economist's ideal of perfect competition. 
market and the international system to function, it suffices that the structure rewards such behavior and that hence some units behave accordingly (Waltz 1979: 92). ${ }^{17}$

If the structure of the international system, i.e., the distribution of power, is to explain state behavior, then what accounts for the structure? States accumulate capabilities in order to assure their security in the face of an anarchic international order. ${ }^{18}$ Capabilities include military, economic and political means. ${ }^{19}$ However, this seems to be a circular argument, leaving undecided whether ultimately structure drives unit behavior or vice versa. Even though Waltz (1979: 98) attributes capabilities to the states, the distribution of capabilities across units is highlighted as a feature of the international system. In analogy to the market system, the international system could be described as an emergent phenomenon, explaining the circular argument. Waltz describes how market structures constrain individual behavior within the market: "From the coaction of like units emerges a structure that affects and constrains all of them. Once formed, a market becomes a force in itself, and a force that the constituting units acting singly or in small numbers cannot control.” (Waltz 1979: 90, emphasis RMR). This kind of emergence also takes place with respect to the international system: "International-political systems, like economic markets, are individualist in origin, spontaneously generated, and unintended. In both systems, structures are formed by the coaction of their units.” (Waltz 1979: 91). ${ }^{20}$

\section{Offensive and defensive neorealism}

For neorealists, the distribution, the relative gains of cooperation, matter (Waltz 1979: 105; Waltz 2000: 39). Therefore, states shy away from cooperation, if it strengthens their partners more than themselves. In the international system, states strive for ensuring their relative position because they are more concerned with their protection against others than with directly strengthening their own good. This is what all neorealists would agree on. Interests or preferences of states are exogenously assumed. ${ }^{21}$ Neorealists claim that states have a "national interest" defined in terms of their survival and security (Waltz 1979: 134). Although this concern for the relative position in the international system is shared by all neorealists, there are differences concerning the motives of states within neorealism, relating to differences in the assumption made about the basic goal that states pursue.

17 A similar argument is made by Beckenkamp (2006: 41/42).

18 The description of the international system as exhibiting an 'anarchic order' or an 'anarchic structure' is an oxymoron (Forde 1995: 145), but since they are the keywords of neorealism, it seems appropriate to use them here.

19 Waltz (1979: 94) considers the common distinction between high and low politics inappropriate, because the different types of capabilities are always used in interconnection by states and therefore such a separation would not be meaningful.

20 It should be noted that the type of emergence referred to by Waltz is different from the constructivist interpretation of emergence in part II and III. The former is closer to the concept of emergence explored by Beckenkamp (2006).

21 This is similar (but not identical) to the profit-maximizing behavior ascribed to firms in microeconomic theory. The microeconomic analogy is the cornerstone of Waltz's materialist and systemic theory. 
Defensive neorealists like Waltz ${ }^{22}$ stress that the basic interest of states is their survival: "In a microtheory, whether of international politics or of economics, the motivation of the actors is assumed rather than realistically described. I assume that states seek to ensure their survival. [...] Survival is a prerequisite to achieving any goals that states may have, other than the goal of promoting their own disappearance as political entities.” (Waltz 1979: 91/92). To this end, they do not maximize their power but they balance power in order to avoid the rise of a hegemony that would deteriorate their position in the system (Waltz 1979: 126). The specific feature of defensive neorealism is that states are content to keep their relative position in the international system, which implies a strong loss aversion. In contrast to this defensive neorealism, offensive neorealists like Mearsheimer (1994/95: 11) conceive of states as aiming "to maximize their relative power positions over other states". This implies that states are not content with their relative power in the status quo, but strive for relative gains. In Mearsheimer's view, states try to gain a comparative advantage, in the sense of altering the distribution of power in the international system to their advantage. Thus, the nuances between offensive and defensive neorealism become apparent when it comes to the assessment of a situation, which maintains the relative status quo between states.

\section{International organizations as instruments of state agency}

What does neorealism have to say about international organizations? International organizations as a form of cooperation depend on the assumed motivation or situation states find themselves in, as discussed above. Since the presumed ultimate goal of states is their individual survival and security, their utility depends crucially on what the other states do. This interdependence has the effect that states cooperate only under the condition that their relative position is at least maintained, irrespective of the amount of absolute gains that would result from such a cooperation. States are even willing to sacrifice absolute gains "if doing so prevents others from achieving even greater gains” (Grieco 1988: 498). Cooperation is permanently questioned, not just due to the uncertainty about the future behavior of the other actors, but even more so due to the fear of a relative power loss. Therefore cooperation is hardly ever stable and is relegated to the formation of alliances; it is generally based on "balancing", which means that states prefer to join the weaker of two coalitions and not on "bandwagoning” behavior (Waltz 1979: 126). ${ }^{23}$

One has to be aware that neorealist theory does not perceive of international relations as being necessarily zero-sum games. Also, in a self-help system, there is "the possibility of cooperating for mutual gain” (Waltz 1979: 105), but in general, the fear of unequal distribution inhibits coop-

22 Grieco (1988: 499/500) and Snyder are also considered as defensive neorealists (cf. Mearsheimer 1994/1995: 11/12, Fn. 27).

23 Later, Waltz specified his theory by distinguishing between strong and weak states in terms of relative capabilities. He conceded (2000: 38) that especially for weak states bandwagoning could appear as an option for survival - although he emphasizes that neorealism does not deal with the specific behavioral responses of states, only with the "pressures of structure on states" (Waltz 2000: 27). By contrast, the anarchic structure of the international system induces great powers to exhibit balancing behavior: "Balancing theory does not predict uniformity of behaviour but rather the strong tendency of major states in the system, or in regional subsystems, to resort to balancing when they have to. That states try different strategies of survival is hardly surprising” (Waltz 2000: 38/39). 
eration (i.e., Pareto-improving gains from cooperation are not realized). However, Waltz (1979: 192) defines 'power' in terms of the distribution of capabilities. Thus, power is a relative or relational category: more power for one state automatically means less for another state. In this respect, the power struggle is a zero-sum game. Both views expressed by Waltz can be reconciled, if the distinction made by Waltz between capabilities (attributed to the states) and the distribution of capabilities (a systemic property) is recalled. From the perspective of states, gains from cooperation are possible and could result, for example, in additional economic resources. However, since states are assumed not to maximize capabilities but to secure their survival, the distribution of capabilities is decisive. In other words: the potential welfare gains do not lead to actual cooperation, because they are associated with shifts in relative power. Thus, the dominant logic of relative position inhibits cooperative behavior. But despite this being the core of the neorealist theory, Waltz shows that there are configurations of the international system where cooperation is possible (e.g., regional integration and alliances). However, cooperation is hardly relevant, because the great powers make the most difference and constitute the basis for Waltz's general theory of international politics. ${ }^{24}$

In a self-help world, states are concerned with their relative position in the international system in terms of capabilities and, hence, they cannot be content with absolute gains if they lose power compared to other states. ${ }^{25}$ Thus states are unlikely to engage in cooperation unless they can expect relative gains, or at least the current distribution of power is maintained. This explains why temporary alliances are the common type of cooperation in a neorealist world (Mearsheimer 1994/95: 9-13). No state can rely on international organizations to provide security, because the primary concern of states is to maintain their relative power (cf. Grieco 1988: 495-503). Nevertheless, cooperative behavior between states is not restricted to temporary coalitions or regional cooperation - quite to the contrary, persistent, global, formalized international organizations seem empirically more frequent. How is this puzzle explained by neorealism?

It has to be pointed out that neorealism acknowledges the existence of international organizations. ${ }^{26}$ However, neorealists argue that international organizations do not develop the same

24 For example, Waltz (1979: 70-73) describes the historic situation of a multipolar system, where the European states were the great powers, as being basically a zero-sum game among European states. Then, with the rise of the bipolar system, regional cooperation in Western Europe had been enabled, although European governments were still interested in the distribution of gains: "Conflicts of interest remain, but not the expectation that someone will use force to resolve them” (Waltz 1979: 71). Thereby Waltz tries to illustrate that the "units of greatest capability" (Waltz 1979: 72) account for the structure of the international system.

25 Concerning the pursuit for relative advantages in order to survive, neorealism is inspired by Darwin's theory of evolution. Survival is a matter of capabilities (i.e. how adapted individuals are to their environments), where besides absolute capabilities the relative fitness also matters. This is known as the process of natural selection. Neorealism has applied this view of evolution to the field of international relations, where states struggle for survival. However, the analogy is rather superficial, since evolution functions in a passive way, i.e., species or genes are not actors in the sense that they actively accumulate capabilities and strive for fitness. Quite to the contrary, evolution is based (among other mechanisms) on random mutations, one of which might turn out to lead to an increased fitness of a species.

26 "International organizations do exist, and in ever-growing numbers. Supranational agents able to act effectively, however, either themselves acquire some of the attributes and capabilities of states, as did the medieval papacy in the era of Innocent III, or they soon reveal their inability to act in important ways except with the support, or at least the acquiescence, of the principal states concerned with the matters at hand" (Waltz 
properties as domestic structures; most importantly, they do not create a hierarchic order. Neorealism has been criticized for its perceived failure to explain why states spend their resources on making international rules, since these rules are not binding constraints. Waltz replied to his critics that institutionalized cooperation is significant, but it needs to be recognized that "international institutions serve primarily national rather than international interests” (Waltz 2000: 21). Morgenthau already claimed that "there is no such thing as the policy of an organization, international and domestic, apart from the policy of its most influential member or members" (Morgenthau 1953: 150). International organizations are an important tool for powerful states to serve what they perceive to be their interests (Waltz 2000: 20). ${ }^{27}$ This view that international organizations cannot be considered as autonomous corporate actors has been expressed even more strongly by the offensive neorealist Mearsheimer:

"Realists also recognize that states sometimes operate through institutions. However, they believe that those rules reflect state calculations of self-interest based primarily on the international distribution of power. The most powerful states in the system create and shape institutions so that they can maintain their share of world power or even increase it” (Mearsheimer 1994/95: 13).

Thus, even in the presence of international organizations, violence is a constant possibility and not only the ultima ratio (Waltz 1979: 113).

Still, cooperation through international organizations at the global level is difficult to explain within the neorealist framework. Surely, Waltz's (2000: 21) claim that powerful states use international institutions for their own interests has some plausibility, and there are indeed examples where powerful states impose their will on international institutions. ${ }^{28}$ But if the strong states find international institutions useful because they strengthen their relative position in the international system, then obviously the question arises why weaker states should agree on such international cooperation. Neorealism has not answered this question to date. The influence of single states in an international organization has to reflect the asymmetry of the international system, but even then, on a global scale, it is impossible for all states to gain, relative to each other! Thus, the existence of international organizations can be either explained by a misperception of some states concerning their relative gains, or by the defensive variant of neorealism, according to which the survival (in the sense of wishing to maintain the position in the system, and not the relative accumulation of power) motivates state behavior. Defensive neorealism might consider international organizations as a means to stabilize the relative position in the international sys-

1979: 88). It seems anachronistic to speak of 'supranational agents' concerning a historic period in time before the rise of the modern nation-state.

27 Waltz (2000: 18-27) illustrates the role of international institutions within neorealist theory by analyzing the continued existence of NATO after the end of the Cold War.

28 For example, Abrahamsson (2003: chapter 2) describes how the United States use the Bretton Woods institutions as a cheap foreign policy tool. Similarly, Wade (2002) argues that the United States has in several ways an exclusive influence over the World Bank, compared to other states, and consequently the "US has found the World Bank an especially useful instrument for projecting its influence in developing countries" (Wade 2002: 217). 
tem, although they know that ultimately their security depends on their individual capabilities. ${ }^{29}$ A possibility to explain international organizations from a neorealist perspective would be to consider issue areas where states play coordination games without distribution conflicts (for example the activities of the International Telecommunication Union). In such settings international organizations can provide useful focal points. However, neorealism is primarily concerned with security issues that are generally conceived as distribution conflicts and, hence, make the explanation of international organizations dealing with these issues difficult.

Therefore, despite neorealism's apparent inability to explain international institutions fully, the bottom line is that international organizations simply serve state interests. Neorealism emphasizes that international organizations constitute an arena for state power and interests. In this view, international organizations are potentially useful instruments to increase state power. Thus, state agency dominates. Neorealism leaves no room for an autonomy of international organizations that would allow to think of them as corporate actors. Especially the materialist ontology constitutes a hindrance to a theory of international relations that would be able to conceptualize international organizations with greater autonomy.

In sum, Neorealism is an individualistic, ${ }^{30}$ materialist $^{31}$ and structural ${ }^{32}$ theory arguing that the positions between states in terms of the distribution of capabilities explain state behavior. Although "emergence" plays an important role in neorealist theory, it does not provide a framework that would explain the autonomy of supranational actors. What emerges in neorealism is the structure of the international system, but not an actor of a higher order.

\section{Rational choice institutionalism}

Institutionalism takes many different forms ranging from functionalist theories to interdependence theories. In contrast to neorealism, they are all optimistic about the capabilities of international institutions to achieve cooperation among states (cf. Grieco 1988: 486). In this section, rational choice institutionalism is considered with regard to the role it ascribes to international organizations. Rational choice institutionalism has been strongly influenced by Robert Axelrod's seminal "The Evolution of Co-operation" (1984) and has become a major approach to international relations, especially following the first publication of Keohane's "After Hegemony" (2005) in 1984. This section briefly outlines the main assumptions and characteristics of this theoretical approach. In order to see the differences between the schools of thought in international relations theory more clearly, rational choice institutionalism is delineated against the background of neorealism.

29 Practically it is doubtful whether international organizations that preserve exactly the relative positions of their members are possible and useful.

30 Neorealism is individualistic in the sense that states are treated as unitary actors, exhibiting preferences or interests similar to methodological individualism in economics with respect to real individuals.

31 Neorealism has a materialist ontology, since ideational factors such as culture and knowledge are not considered ex definitionis.

32 Neorealism is a structural or systemic theory, because state behavior is explained with systemic properties. 


\section{States as rational, self-interested actors with given preferences}

Basically, rational choice institutionalism applies rational choice theory to states instead of individuals as the main actors. The fundamental assumption is borrowed from microeconomics: States act rationally in the sense that they maximize their utility. The preferences or interests are exogenous and assumed to be constant. This is due to the methodological purpose of attributing changes in state behavior to changes of restrictions instead of preferences. ${ }^{33}$

Institutions are an important part of these restrictions. Keohane emphasizes that "[i]nstitutions, interpreted within a rational-choice framework, affect the context of choice and therefore the opportunity costs of alternatives” (Keohane 2005: 80). At the same time, institutions - at least as far as international organizations are concerned - are the intended outcome of state action, i.e., institutions are implemented in order to realize mutual welfare gains (Keohane 2005: 80-83). This is a functionalist explanation of institution-building which implies that institutions are conceptualized as mere instruments enhancing state utility, and not as a goal in themselves. This functional or instrumental view of institutions (and consequently also of international organizations) is fundamental to rational choice institutionalism: "Our basic presumption, grounded in the broad tradition of rational-choice analysis, is that states use international institutions to further their own goals, and they design institutions accordingly” (Koremenos/Lipson/Snidal 2001: 762). So in this respect, rational choice institutionalism starts from similar assumptions as neorealism, since nations are assumed to behave according to their perceived interests.

\section{Absolute, not relative, gains and the enforcement of cooperation}

Grieco (1988: 495-503) however, emphasizes that neorealism and rational choice institutionalism are fundamentally different approaches to international relations. According to Grieco, rational choice institutionalism is based on an atomistic view of states that maximize their individual utility, irrespective of what other states do. If cooperation provides them with absolute gains, they will undertake it; otherwise they will refrain from cooperation. In contrast, according to neorealism, states are more reluctant to cooperate. As shown above, this is the case because absolute gains ${ }^{34}$ are no sufficient condition to generate cooperation. ${ }^{35}$ A further difference between

33 Interdependent utility functions are generally possible and also necessary, if international security is assumed to be part of the utility functions of states.

34 In this debate (Grieco/Powell/Snidal 1993), Powell and Snidal - in contrast to Grieco - stress that neorealism and rational choice institutionalism have much in common. For example, Snidal argues that as the numbers of actors increases, the relative-gains motivation of states becomes less relevant for bilateral cooperation. By the same token, Powell argues that it is more fruitful to assume that, in general, states maximize absolute gains, but due to specific strategic environments a state may be inclined to take its positionality into account. Therefore he emphasizes that the debate between neorealism and rational choice institutionalism about absolute and relative gains is not just "a debate about what to assume about states' utility functions" (Powell 1994: 335). Focussing exclusively on the utility functions excludes the possibility that the concern for relative gains follows from the structure of the international system in which the states act (cf. Powell 1994: 334338). Thus, the debate should be about the utility function of states and its restrictions.

35 The core neorealist assumption that the utility function of states depends crucially on their relative position in the international system is compatible with rational choice analysis, if interdependent preferences are allowed for. This has become an important strand in behavioral economics, whose insights could be beneficial for a broader theoretical underpinning of neorealism. For example, inequity aversion models (cf. Bolton/Ockenfels 2000, Fehr/Schmidt 1999) emphasize the importance of distributional outcomes. The inequity aversion of 
neorealism and rational choice institutionalism is that for the latter theory, the utility functions of states are independent of each other. Thus, in rational choice institutionalism, if there are gains to be made; only the risk of being cheated and to receive a low payoff possibly inhibits cooperation among states. This sharply contrasts with the definition of state interests relative to other states in neorealism.

Based on the assumption that states maximize their absolute gains, rational choice institutionalism perceives international organizations as intentionally created in order to solve international collective action problems (cf. Keohane 2005, Koremenos/Lipson/Snidal 2001, Abbott/Snidal 1998: 6, Stein 1995). In other words, international organizations are potentially helpful for realizing mutual benefits. This is because they are able to solve different types of problems deriving from transnational externalities, information asymmetries, transaction costs, etc. For example, Martin (1999) refers to the comparative advantage international organizations exhibit when removing cooperation obstacles due to the information they provide. In an overview of this literature, Simmons/Martin (2002: 195-197) refer to the different attempts to differentiate systematically between types of collective action problems (e.g., collaboration vs. cooperation problems, different game structures). All these attempts have a functionalist logic in common: "states build institutions in order to achieve collectively desirable outcomes” (Simmons/Martin 2002: 196).

According to rational choice institutionalism, the mutual benefit arising from international collective action in specific dilemma situations is a sufficient motivation for the creation of international institutions sustaining these gains. Rational choice institutionalism does not restrict its definition of gains to security as implied by neorealism but includes, for example, economic issues. This is because the independent variable of the utility function contains welfare beyond the narrow security notion. Thus, rational choice institutionalism can be described as treating "institutions as rational, negotiated responses to the problems international actors face. We can con-

players is a possible explanation for some experimental results that exhibit systematic deviations from payoff maximizing behavior (especially in ultimatum and dictator games). Alternative explanations are given by reciprocity-models that focus on how players judge and reciprocate the kindness of actions not just by their material outcome, but also by evaluating the intentions of the actor (cf. Falk/Fischbacher 2006, similar but including sequential revision, i.e., taking into account how the evaluation of the other players' belief changes during the game: cf. Dufwenberg/Kirchsteiger 2004). However, two important points have to be addressed if insights from behavioral economics are to be used by neorealism. First, in a way, behavioral economics and neorealism have opposite motivations. This strand of behavioral economics tries to model social preferences in order to find a general theory that equally explains selfish and fair behavior. Fairness implies in these models that individuals care for the others, and that gains are not distributed inequitably, but in line with some fairness norm. According to neorealism, the distribution of gains and resources also matters for the utility of actors, but the sign in the utility function is negative. Therefore, whereas a "fair" distribution of gains ceteris paribus increases utility for actors with an inequity aversion, it would decrease the utility of a state under neorealist assumptions. Second, it is now widely accepted that the environment is very important for determining whether fair or selfish behavior prevails (cf. Falk/Fischbacher 2006: 306/307, Fehr/Schmidt 1999: 834-836). In bilateral games with two players, inequity aversion and reciprocity often dominate. By contrast, in games with more than two players and competitive pressures, fair outcomes are unlikely because they cannot be enforced by a single player. However, if a market game with proposer competition is slightly changed (cf. Fehr/Schmidt 1999: 834-836), so that the proposer has the possibility to withdraw his proposal in the third stage, then this constitutes a mechanism to punish inequitable behavior. Hence, in this case, "inequity aversion greatly diminishes the role of competition“ (Fehr/Schmidt 1999: 835). Since this case is unlikely in an anarchic environment, competition and selfish behavior is indeed the dominant logic in a neorealist world. 
nect our definition of institutions to the language of game theory, where institutions are aspects of equilibria, including the rules of the game and the expectations of the actors." (Koremenos/Lipson/Snidal 2001: 768). This accounts for the contractual stance ${ }^{36}$ on institutions and explains the focus of rational choice institutionalism on institutional design in a way that is supposed to generate the 'right' incentives. ${ }^{37}$ Accordingly, the anarchy of the international system and the self-interest as the dominant motivation driving state action lead to strategic situations. Game theory helps to understand the strategic situation states find themselves in and what kind of solutions are available given the rationalistic behavioral assumptions. In this respect, rational choice institutionalism is not a genuine theory of international relations. It is much broader, explaining cooperation on different levels from personal relationships up to the international level.

For instance, if states find themselves in a prisoner's dilemma, there is a strong incentive for each state not to cooperate or to refrain from cooperation. Repeated interaction (with infinite horizon) is likely in international relations and able to foster the emergence of strategies of reciprocity, especially tit-for-tat, making Pareto-improving cooperation more likely (cf. Axelrod 1984, Axelrod 1981). ${ }^{38}$ Repeated interaction is also known as the 'shadow of the future' which stabilizes and ultimately enables cooperation. Axelrod (1984: 185-191) already emphasized that international relations exhibit a large shadow of the future, because at least the major states can be almost certain to interact again with each other in the future. One reason is that the Westphalian system made the nation state a permanent, reliable actor and thereby enabled the emergence of a shadow of the future. The same shadow of the future that fosters cooperation in a rationalistic setting is - in a neorealist world - responsible for the mutual fear and uncertainty

36 In this respect, rational choice institutionalism is in the tradition of the 'contract view of the firm' (Coase 1937, Alchian/Demsetz 1972, cf. also Foss 2000: xxxi). In the definition by Coase, firms are nothing but market contracts with the special characteristic of continuity in the contractual relationship between those who own the capital and labor inputs. Coase argues that contracts are replaced by the hierarchical structure of the firm if this enhances efficiency. Thus, firms are normally created in order to save costs associated with the use of the price mechanism of the market (Coase 1937: 390-392). A different reason for establishing firms is given by Alchian and Demsetz. According to them, shirking in joint team production is monitored more efficiently in firms. However, they stress that unlike the view of Coase, the firm is not an authority, but a "contractual structure subject to continuous renegotiation" (Alchian/Demsetz 1972: 794, emphasis RMR). Whether firms are hierarchies based on long-term contracts or arrangements of continuous contracting has important implications for the application to international organizations. It has to be explained why international organizations are created instead of temporary ad hoc alliances on the basis of single contracts. Abbott/Snidal (1998: 9) apply the argument made by Coase to international organizations: centralization enhances efficiency. Nevertheless, rational choice institutionalism conceptualizes international organizations from a contractual point of view: as contracts between member states in order to solve specific collective action problems (even though it can be useful to grant autonomy to the international organization: see below).

37 This reflects one of the basic insights of Olson's group theory. As the number of members of a group increases, the provision of collective goods is likely to decrease below a collectively optimal level. In order to avoid this erosion of collective action, incentives or compulsion are necessary (cf. Olson 1968: 47).

38 According to standard game theory, the emergence of cooperation crucially depends on the infinite or unknown ending of interaction. If an end period is known (finite games), game theory suggests that noncooperative behavior prevails in all periods, because rational players would use a backwards induction from the final period where sanctioning through future decisions is not available. However, the degree of rationality necessary for this game-theoretical outcome contradicts experimental results, according to which induction is normally limited to the last couple of rounds (cf. Selten/Stoecker 1986). This finding is known as the “chain store paradox" (Selten 1978). Moreover, even if strict rationality of the actors is assumed, cooperation in finite repeated prisoner dilemmas is possible if informational asymmetries exist (cf. Kreps et al. 1982). For an application to competition theory, cf. Engel 2006: 11-20. 
among states, which presses them to defend their relative position or even look for relative, rather than absolute, gains (cf. Waltz 2000: 39).

However, cooperation is not identical to creating institutions or even organizations. Institutions can reduce monitoring and punishment costs while establishing or enhancing the iterativeness of cooperation. The overall incentives for states to cheat can thereby be strongly reduced, and cooperative behavior is more likely. Again, the crucial assumption is that states do not care for their relative positions and engage in cooperation as long as the cooperation is Pareto-improving. From this viewpoint, the emphasis is on the institutional fine-tuning that has to warrant that the incentive structure of the institution generates absolute gains, at least for some, without imposing losses on cooperation partners.

The most important barrier to cooperation in a neorealist world is the concern for relative power. Since rational choice institutionalism is not concerned with relative, but with absolute gains, this neorealist barrier to cooperation is surmounted. Moreover, rational choice institutionalism provides a framework that is able to overcome cheating. The bottom-line is that cooperation is more likely or easier under an institutionalist than under a neorealist paradigm.

The rational choice methodology reconciles the dichotomy between conflict and cooperation that has characterized the field of international relations for so long: While realists consider international relations to be intrinsically conflictual, ${ }^{39}$ idealists emphasize the cooperative nature. In game-theoretic terms, conflict and cooperation depend on the situational factors (payoffs, discounting, time-horizon etc.) of the game (cf. Kratochwil/Ruggie 1986: 762). If there is the possibility to conclude binding contracts, then cheap talk is avoided, and thus cooperative solutions enforced. Because rational choice institutionalism focusses on the variability of situational factors and holds the preferences constant, it is neither realist nor idealist, but rather indifferent, being open for incorporation of both types of behavior.

The fact that rational choice leaves behind the old divide between idealist and realist beliefs concerning states, and ultimately human nature, is important. However, the focus here is on the comparison of how neorealism and rational choice institutionalism respectively conceive of international organizations. Rational choice institutionalism assumes that state behavior is motivated by the own (non-relational) interest of states; therefore, Pareto-improving cooperation is desirable. Problems arise whenever states find themselves in a strategic situation that inhibits the realization of gains from cooperation. International organizations could then be part of the cooperative solution, because sometimes they make Pareto-improvements for states possible.

\section{Reductionism and autonomy}

The aforementioned debate over relative position versus absolute gains from cooperation is very important for answering the question under what circumstances (incentive structures, positionali-

39 'Intrinsically' either in the sense of being part of human nature, or as a systemic property of international relations. 
ties) international institutions are likely to emerge, and what is or will be their scope in international relations. Both approaches - neorealism and rational choice institutionalism - are reductionist in the sense that states are the only relevant (corporate) actors in international relations. International organizations are instruments used by states - irrespective of whether they are used to preserve an existing balance of power, as neorealism would suggest, or whether this kind of institutionalized cooperation maximizes individual state utility.

This description of rational choice institutionalism has focused on its classic features that constitute this rationalistic, individualistic and materialistic theory. Obviously, some important developments within this fast-growing mainstream of international relations theory have been omitted. A full picture cannot be given here, but it seems useful to highlight some developments in order to show the growing complexity of rational choice institutionalism.

Some rational choice institutionalist argue that a microfoundation of states' interests is required in order to make the preference formation of states endogenous. Especially the politics that are internal to states have to be considered. Thus, the unitary actor assumption has been relaxed, emphasizing instead that individuals are the relevant actors providing the basis for the formulation of state interests (cf. Moravcsik 1997, Gourevitch 2002 and Frey 1997: 113-119). ${ }^{40}$ In a way, the state can be interpreted as a solution of some collective action problem between individuals (cf. Stein 1995: 122). Thereby, the functionalist argument made on the level of the international system would be transposed to the lower level of domestic politics (or vice versa). In this view, states are also mere instruments and functions of individual interests.

Ultimately, this implies that there is nothing 'above' the individual - corporate actors would be just a 'useful fiction'. It suggests conceptualizing international organizations as the result of a long chain of several principal-agent relationships. Public choice literature has endorsed this perspective (Frey 1997). For instance Vaubel (2006) identifies four separate principal-agent relationships leading to international organizations. Therefore, international organizations are the furthest removed from control through the votes of citizens, compared to other political actors. This raises questions regarding the accountability and the democratic legitimacy of international organizations. Accordingly, the autonomy of international organizations is a default, resulting from imperfect incentive structures giving leeway to the agents at different stages between the voters and the executive of an international organization (Vaubel 2006). ${ }^{41}$ Thus, international organizations are perceived as accidentally autonomous.

Apart from this case of accidental autonomy, the microfoundation of the state does not provide additional information relating to an explanation of the emergence of (partly) autonomous inter-

40 It has to be noted that Moravcsik (1997) presents his liberal theory of international relations as an alternative to both institutionalism and realism. Here, his theory is treated as an extension of rational choice institutionalism, since its methodology and ontology are similar, simply extending the level of analysis by breaking up the 'state as unitary actor-assumption'. The same applies to Gourevitch (2002: 319), who argues that focussing on domestic politics provides a promising avenue for integrating ideas and norms as explanatory variables into material and institutional frameworks.

41 One reason might be that the agents see themselves accountable to different principals (not just their electorate), in the sense of playing a two-level game. 
national organizations. Quite to the contrary, it strengthens the bottom-up view by adding an individualistic substructure to the state-centered explanation of international organizations. A possible escape from this reductionist view is proposed by Putnam (1988), who argues that governments are engaged in two-level games, trying to reconcile international and domestic pressures. This is a very promising avenue for explaining the state as a corporate actor. Unfortunately, this explanation seems less suited for international organizations, because there are no pressures 'above' international organizations that would discard reductionist explanations.

A different escape from reductionist explanations is present in the approach by Abbott/Snidal (1998). They pursue a basically rationalist perspective on international organizations, but add social constructivist elements. ${ }^{42}$ In their view, international organizations are to some degree autonomous - not just because this enhances efficiency, but also because autonomy constitutes a precondition for their ability to "shape understandings, influence the terms of state interactions, elaborate norms, and mediate and resolve member states' disputes”. Thereby, the "acts of independent IOs [international organizations] may be accorded special legitimacy, and they affect the legitimacy of members’ actions.” (Abbott/Snidal 1998: 9). Still, "IO autonomy remains highly constrained by state interests” (Abbott/Snidal 1998: 9). This is reconciled by claiming that international organizations are created to be autonomous within certain boundaries. The risks associated with this autonomy are knowingly taken into account by the states, because it is the autonomy accorded to international organizations which makes them useful for the states. Therefore, Abbott/Snidal (1998:8) claim that "[s]tates consciously use IOs both to reduce transaction costs in the narrow sense and, more broadly, to create information, ideas, norms and expectations”.

This shows that even in an individualist rational choice framework it is to some extent possible that states decide to create an autonomous international organization. The motivation could be that limited autonomy vis-à-vis their constituencies is a necessary collateral of the problemsolving activities of the organization. Assuming complete rationality, the net present benefit a state reaps from an international organization resolving a specific problem has to be higher than the cost incurred from ceding sovereignty to the organization. Thus, limited autonomy could be the result of a rational delegation of power to an international organization, thereby avoiding the assumption of a preference for autonomous international organizations as a Deus ex machina solution.

Both the debate whether an autonomy of international organizations is conceivable as well as the debate over relative position versus absolute gains from cooperation are concerned with explaining the creation and the nature of international organizations. Unfortunately, they address only

42 It has become very common to include social constructivist elements into rationalist frameworks. For example, Keohane has tried to make rational choice institutionalism more open by stressing that international institutions also have constitutive aspects in the sense of influencing the interests of states. Hence, the role of international institutions is not limited to its core function of enabling cooperation (cf. Hansen 1996: 28). Against this background, Keohane (2002) further argues that the "instrumentalist" and the "normative optics" on international law should be combined. Unfortunately, it appears very difficult to integrate such a "normative optic" into the rational choice framework. In a similar attempt, Goldstein/Keohane (1993) enhance their rational approach to foreign policy by taking the role of ideas into account. For a critical account of these attempts to incorporate 'ideas' into a rational choice institutionalist framework see Woods (1995). 
implicitly the question of the impact and power of international organizations. Neorealism does not see any autonomous power in international organizations, whereas, according to rational choice institutionalism, international organizations can be powerful if this is a necessary condition for the realization of a Pareto-improving situation. What autonomy exactly signifies, its consequences for states apart from benefits and $\operatorname{costs}^{43}$ is beyond the analytical scope of rational choice. This is due to methodological individualism which makes variations in the utility function impossible. Thus, the consequences, feedbacks and alterations of the utility function (or motivation) of states that are associated with the autonomy of international organizations cannot be captured with the analytical toolbox of rational choice.

To sum up, both theories treat international organizations as a possible outcome of state interaction and agency. In the rational choice institutionalist case, autonomy is a possible outcome, but the emerging endogenous dynamics resulting from the creation of (partly) autonomous international organizations are disregarded. However, these are crucial for assessing how international organizations, through the accumulation of specific knowledge and expertise, might influence state interests and identities. Hence, neorealism and, to a lesser extent, rational choice institutionalism are reductionist, because they treat international organizations simply as "epiphenomena of state interaction” (Barnett/Finnemore 1999: 704).

\section{Foundations for a conceptualization of emergent international or- ganizations}

\section{Symbolic interactionism}

Neorealism and rational choice institutionalism have two important deficits that stem from their ontology. First, the attention of both theories is limited to materialist phenomena, and second, they focus exclusively on individual behavior or structures. Despite the aforementioned attempts to include social constructivist insights into rational choice institutionalism, the ontology is responsible for excluding and neglecting ideational factors as well as preference and identity formation in their research agenda. By drawing on insights from social psychology, social constructivism $^{44}$ in the tradition of Alexander Wendt has tried to bring those issues back on the agenda of

43 What benefits and costs are is defined by the assumed utility function.

44 Constructivism is a heterogeneous line of thought. Nevertheless, two understandings build a common ground: social reality is constructed due to the a priori classifications in our minds. This epistemological insight goes back to Kant's "Critique of Pure Reason" and has been considered as a "Copernican revolution" because perception does not just mirror some objective reality. Experience and the classifications in our minds necessarily go together. Moreover, scientific knowledge, hence the instruments that are used to interpret social reality, is constructed as well. In sum, constructivism is founded on the insight that knowledge and the material world are variant and mutually constitute social facts (cf. Adler 2002: 95 and Weller 2005). This does not imply that social constructivism negates the existence of an objective material reality. According to Onuf (1989: 40), constructivism "does not draw a sharp distinction between material and social realities [...] and it does not grant sovereignty to either the material or the social by defining the other out of existence. It does find socially made content dominant in and for the individual without denying the independent, 'natural' reality of individuals as materially situated biological beings". For an overview on the evolution and strands of constructivism in international relations, see Adler (2002). For the foundation of constructivism in the phi- 
international relations theory. In order to uncover the roots of social constructivism, the symbolic interactionism of Mead (1964) is outlined briefly in the next section.

Mead (1964: 19-43), in his social psychology, describes how the self is constituted by taking the perspectives of others. The human ability to be sympathetic and empathic towards others is fundamental in this view of social preference and identity formation. Thinking is a process in which humans simulate arguments of others and engage in an "inner forum” (Mead 1964: 34). This social process, this "inner flow of speech" (Mead 1964: 39), is possible in isolation, a situation Mead refers to as a "Robinson Crusoe” context. This intrapersonal focus pursued by Mead's theory has been labeled "micro-sociology" by others (cf. Giddens 1979: 50). However, the ability to take attitudes and roles of others is not innate. The mental process is part of the social process. Without socialization, individuals would be unable to engage in an inner flow of speech. The social constitution of the self takes place subconsciously in an evolutionary process, embedded in a wider social evolution: ${ }^{45}$

“A self can arise only where there is a social process within which this self has had its initiation. It arises within that process. For that process, the communication and participation to which I have referred is essential. That is the way in which selves have arisen. That is where the individual is in a social process in which he is part, where he does influence himself as he does others. There the self arises” (Mead 1964: 42).

Since social constructivism is based on these insights of symbolic interactionism, it is opposed to standard game-theoretic approaches, because variation and socialization of preferences are not excluded, but a central research interest. Social constructivism opens up the "black box" of interest and identity formation. Wendt acknowledges that interest and identity formation are already increasingly taken into account by rationalists, but sees substantial deficits regarding the consideration of symbolic interactionism which emphasizes the "construction effects of interaction on identities and interests" (Wendt 1999: 170/171). Applied to the interaction between states, and thereby assuming that states develop something that can be called 'identity', symbolic interactionism has important implications, which are explored in the next section.

\section{Social constructivism: inter-state practice matters}

These effects of interaction described by Mead (1964) are transposed in Wendt's theory to the interaction of states. Repeated interaction between states has two effects on their identities and interests: First, by interaction, actors learn "to see themselves as others do" (Wendt 1994: 390). The impact of this change in perspective on the own identity is stronger if the perceived depend-

losophies of Kant and Wittgenstein, see Onuf (1989: 35-52). The social constructivist approach is sometimes referred to as “cognitivism” or "knowledge-based theories” (Hasenclever/Mayer/Rittberger 1997: ch. 5).

The individual finds himself in a dialectical process with society, as Berger/Luckmann (1991: 149-182) have described it. See also their differentiation between primary and secondary socialization and their suggestion to follow the research path which they describe as "sociological psychology" (Berger/Luckmann 1991: 208) in the tradition of Mead. 
ency on the other is high (and vice versa). Second, actors teach others and themselves to cooperate and thereby learn to identify with each other. Ultimately, interaction on a regular basis transforms "an interdependence of outcomes into one of utility" (Wendt 1994: 390). To illustrate his point, Wendt (1992: 417) refers to the European integration: Almost 50 years of cooperation has created a collective European identity which has an impact on national interest formation.

Clearly inspired by symbolic interactionism, Wendt's view on state interaction was a departure from older theories of international relations. In a nutshell, his social constructivist theory of international relations is set forth in the title of his seminal article "Anarchy is what States make of it: the Social Construction of Power Politics” (Wendt 1992). Wendt contests the neorealist claim of a causality between anarchy and the focus on relative power and self-help of states. Instead, he argues, such a Hobbesian interpretation of the international system is only one possibility besides a Lockean and a Kantian anarchy or culture (see Table below). Which type of anarchy dominates depends on how states interact (cf. Wendt 1992: 396-404). In other words, the practices of states create structures of identities and interests that can be one type or another. A selfhelp world is not an automatism resulting from the structure of the international system. Rather, “power politics are socially constructed under anarchy” (Wendt 1992: 396). Depending on the 'practice' of states, different cultures are established. It is up to the states to make something out of anarchy. ${ }^{46}$

The 'practice' of states is central to Wendt's social theory of international relations since it resolves the agent-structure problem (cf. Wendt 1992: 413). ${ }^{47}$ Neither do the preferences of the agents determine the structure of the international system, nor vice versa. Wendt (1987: 355-361) stresses that agents and structures are mutually constituted through the regular processes of practices. $^{48}$ Still, social structures and agents remain ontologically distinct entities. Similarly, Onuf (1989: 36) points out that in "simplest terms, people and societies construct, or constitute, each other”. The advantage of this “structuration theory” (cf. Giddens 1979: 69-73, Wendt 1987 and 1999, chapter 4 ) is that its co-determination of social phenomena avoids both the fallacies of re-

46 It should be noted that Wendt distinguishes three degrees of internalization of these cultures, measuring how strongly the respective culture affects the interests and identities (cf. Wendt 1999: 266-278).

47 The agent-structure debate in international relations (cf. Adler 2002: 104-106) largely reflects the more sociological debate on how individuals and society relate to each other (cf. Durkheim 1965). Bhaskar (1982, 1998) developed a transformational model that reconciles reductionist and holist explanations of society. He attributes a "dual character" to both, society and human action. Society is the condition as well as the outcome of human action. In turn, human action consciously produces society, but at the same time unconsciously reproduces or transforms the social conditions of their activities (cf. Bhaskar 1998: 31-37). Bhaskar (1998: 36) regards society "as an ensemble of structures, practices and conventions which individuals reproduce or transform, but which would not exist unless they did so. Society does not exist independently of human activity (the error of reification). But it is not the product of it (the error of voluntarism)." Wendt's social theory of international relations and in particular his resolution of the agent-structure debate draws on these theoretical foundations (cf. Wendt 1987: 361).

48 The importance of 'practice' as a point of departure for social constructivism is also stressed by Onuf (1989: 35-43). Wendt (1987) reconciled and surmounted the division between ontological individualism and structuralism. This is considered as an important foundation of the constructivist turn in international relations theory (cf. Ulbert 2005: 16/17). Moreover, the fact that Wendt transcends the boundaries between methodological individualism and collectivism makes his social theory open to include existing theories of international relations as specified cases of his general theory. 
ductionism (individualism) and holism (determinism). Thus, the common dualism between structural determination on the one hand and actor autonomy is avoided (cf. Risse 2007: 128-132).

The problem arising from the mutual constitution is that the independent variable remains unclear. If a Hobbesian, a Lockean or a Kantian culture results from practice, then what drives practice? And what triggers a change of practice? Wendt argues that there is no automatic evolution from a Hobbesian towards a Kantian state of the world. Cultures exhibit an inertia and are self-fulfilling prophecies that makes change difficult (cf. Wendt 1999: 309). However, he points out, that devolution is very unlikely. This means that it is very unlikely for the international system, once it has developed a Lockean or Kantian culture, to fall back permanently into a Hobbesian world of mutual aggression. Quite to the contrary, violence and destruction provide incentives to evolve from a Hobbesian to a Lockean and further to a Kantian culture (Wendt 1999: 311). If and when this evolution will take place is undetermined, but Wendt (1999: 312) is optimistic that "the history of international politics will be unidirectional".

With respect to the Lockean world, Wendt establishes two necessary conditions for state sovereignty as dominant practice of state interaction to arise. The density and regularity of interaction must be high and "actors must be dissatisfied with preexisting forms of identity and interaction" (Wendt 1992: 414). If states acknowledge the sovereignty of others, then this will become the norm. First, practicing sovereignty leads states to define their security in terms of property rights over a territory. Once this norm is internalized, states are respectful toward other states' territories. Finally, on the basis of this socialization, states rely less on their national military powers to ensure their security (see Table 1 below). Instead, resources are shifted due to the insight that collective recognition of state sovereignty makes the power resources of others less threatening (Wendt 1992: 415). This international culture enables states to engage in more direct forms of cooperation. However, table 1 indicates that different cultures or practices of state interaction are possible. The prevailing norms and identities (and thus also the conception of international security) depend on the type of culture that is effective. Therefore, it can be concluded that social constructivism is a general theory of international relations, accommodating for potential different structures and logics of the international system (realist, idealist or institutionalist). This implies that real-world policies could also be interpreted as driven by self-help considerations within a social constructivist framework. 
Table 1: Three possible cultures of anarchy according to Alexander Wendt (1999: ch. 6 and 1992) and the emergence of international organizations (own depiction)

\begin{tabular}{|c|c|c|c|}
\hline & Hobbesian World & Lockean World & Kantian World \\
\hline $\begin{array}{l}\text { The practice of state } \\
\text { interaction... }\end{array}$ & enmity & sovereignty & friendship \\
\hline $\begin{array}{l}\text {...generates norms } \\
\text { and identities. }\end{array}$ & $\begin{array}{l}\text { self-help (relative } \\
\text { position matters) }\end{array}$ & $\begin{array}{l}\text { egoistic (absolute } \\
\text { gains matter) }\end{array}$ & $\begin{array}{l}\text { rule of non-violence } \\
\text { and mutual aid }\end{array}$ \\
\hline $\begin{array}{l}\text { Conception of } \\
\text { security }\end{array}$ & competition & property rights & $\begin{array}{l}\text { pluralistic security } \\
\text { community }\end{array}$ \\
\hline $\begin{array}{l}\text { Synthesis of inter- } \\
\text { national relations } \\
\text { theories }\end{array}$ & realism & institutionalism & idealism \\
\hline $\begin{array}{l}\text { Degree of inter- } \\
\text { national organization } \\
\text { emergencelautonomy }\end{array}$ & $\begin{array}{l}\text { international organiza- } \\
\text { tions without emergence } \\
\text { (i.e. state agency } \\
\text { dominates) }\end{array}$ & $\begin{array}{l}\text { international organi- } \\
\text { zations without emer- } \\
\text { gence but limited } \\
\text { autonomy (i.e. state } \\
\text { agency dominates) }\end{array}$ & $\begin{array}{l}\text { emergent international } \\
\text { organizations } \\
=\text { corporate actor }\end{array}$ \\
\hline
\end{tabular}

Wendt's social theory is a structural idealist theory, in contrast to structural materialist (neorealism) and individual materialist (rational choice institutionalism) theories of international relations. 'Social construction' signifies that shared ideas play a key role in the generation of cultures, interests and identities. In contrast to the neorealist claim, it is not the distribution of power that accounts for systemic forces, but the distribution of ideas which matters for how actors define their interests and identities (cf. Wendt 1999: 113-135). ${ }^{49}$

\section{Emergence, autonomy and power of international organizations}

\section{International organizations as emergent high-order corporate actors}

In the previous two sections, social constructivism in the tradition of Wendt has been described without referring to international organizations. This lapse is made up for subsequently. Social constructivist approaches are used to reach a conceptualization of international organizations as emergent high-order corporate actors.

49 For example, social constructivism provides an ideational interpretation of globalization that departs from traditional Marxist views, because it insists on the "relative autonomy of institutions and ideas from underlying economic configurations” (Risse 2007: 138). In a broad sense, social constructivist literature has provided sufficient evidence that globalization is not just economic but ideational in terms of emerging global cultures and norms (cf. Risse 2007: 133-136). 
International organizations are structurally analogous to other corporate actors such as firms. However, they differ from firms (among other things) in terms of order or level. International organizations are high-order corporate actors because their members/constituencies are not individuals but states, which can be corporate actors themselves. ${ }^{50}$ This relates to the finding that the distinction between structure and agents depends on the level of analysis. According to the 'level of analysis' argument in international relations theory (cf. Adler 2002: 105), the international system can be the structure vis-à-vis international organizations or states as agents. On a lower level, the state can be the structure and bureaucracies are the agents. The lowest level is the corporate actor with individuals as agents. All other corporate actors are higher-order corporate actors, because they presuppose low-order corporate actors.

Therefore, the 'corporate actor problem', that is, the question of whether or not the interaction of individuals/units creates something which is more than the sum of its parts, resurfaces on different levels. The basic question is the same, irrespective of the level: analogous to individuals constituting a firm, a state, a club or a family, states constitute international organizations. Both on the national as well as on the international level, individualist and holist explanations are opposed to each other. The concept of emergence combines/synthesizes these approaches. It assumes, on the one hand, that individuals constitute the corporate actor and thereby create a "surplus”. On the other hand, it assumes that individuals cannot be seen as the sole explanatory variable, since they are influenced by feedback from the corporate actor. Implicitly, the emergence of states as lower-order corporate actors is presupposed here.

It has been outlined in the first part of this chapter that neorealism and rational choice institutionalism look at states as the principal acting unit. ${ }^{51}$ Thus, apart from the significant exceptions noted earlier, states are generally seen as corporate actors, whereas this actor quality is denied to international organizations. This is depicted in the last row of Table 1. In a Hobbesian setting, international organizations, if they are created at all, are not emergent corporate actors, because state agency dominates. In a Lockean world, international organizations are more common forms of cooperation; however, they are not emergent corporate actors, because state agency dominates, too. However, as outlined above, limited autonomy is possible. It is limited because it is only granted insofar as it is necessary for the organizations to exert their functions properly.

The next section turns to the case of emergent international organizations. It is deemed to explain how states as low-order corporate actors create international organizations and how those attain the status of autonomous corporate actors (the lower right case in table 1 referring to Kantian

50 Of course, firms can also be composed of other corporate actors, but international organizations are virtually exclusively composed of low-order corporate actors.

51 Generally, states are taken as shorthand for the internal decision-making processes. In contrast, Wendt (2004) argues that states are persons. This discussion is sidestepped here (cf. fn. 57), but it is important to notice the assumption that states are autonomous corporate actors. It is not intended to claim that domestic politics are not relevant for state action. Indeed, it seems plausible that states play two-level games in the sense of Putnam (1988). 
culture). As a simplification, it is assumed that international organizations are solely created by states (which is not entirely correct). ${ }^{52}$

In general, the 'emergence' concept seeks to explain the behavior of collective actors without exclusively referring to the properties and actions of its units. ${ }^{53}$ Institutions created to resolve collective action problems transform not just incentive structures, but also identities and interests through an altered cognition. Initially, cooperation has probably been undertaken for rational, egoistic reasons but subsequently, by regular practice, it has been internalized by the agents' identities (cf. Wendt 1992: 417). Thus, international organizations emancipate themselves from their original context and become partly independent. ${ }^{54}$ This social constructivist interpretation of emergence is expressed by Wendt (2004: 302-305): “in the emergence approach individual intentions are constituted by the shared meanings in which they are embedded, making the relationship between individual and group intentions mutually constitutive rather than asymmetric" (Wendt 2004: 304/305). This is the core of symbolic interactionism, transposed by Wendt to the field of international relations. Norms, rules, legitimacy and cultures matter in his social constructivist theory, because they constitute the practice of international interaction and thus have an impact or, more precisely, feedback on the identities and interests of states. The type of feedback leading to emergence is vertical, because it is between the corporate actor and his constituencies. ${ }^{55}$ International organizations have changed the world in which states operate. If Meads' social psychology is applied to states, then international organizations are part of the societal

52 International organizations are normally composed of member states or, more generally, of lower-order corporate actors. However, the predominance of state membership does not imply that state governments are always the founders of international organizations. Quite to the contrary, international governmental organizations are created for the most part by other international governmental organizations (cf. Shanks/Jacobson/Kaplan 1996: 599/600). In this case, states that are members of the parent organization automatically become, by passive assent, members of the newly created international organization (cf. Shanks/Jacobson/Kaplan 1996: 599). This dominant emanated type of international organizations is supposed to exhibit more autonomy, vis-à-vis its member states, than 'traditional' international organizations, because the former are constituted through the normal decision-making procedures of other international organizations and not through classic international treaties. Generally, states are more influential in international treaties than in internal organizational procedures (cf. Shanks/Jacobson/Kaplan 1996: 599/600); thus, international organizations that are emanated from other international organizations are more detached from the pressure of state interests than 'traditional' international organizations. However, these emanated organizations are considered to be less stable than traditional, treaty-based organizations (cf. Shanks/Jacobson/Kaplan 1996: 600).

53 This is a fundamental principle of sociology that applies to society in general. Since society cannot be reduced to its entities, Durkheim (1965: 94) characterizes society as a "synthesis sui generis" [own translation].

54 Apparently, this view is shared by the sociology of organization, which claims that "organizations are not simple mechanical tools obediently doing the work of their creators” (Ness/Brechin 1988: 246/247).

55 This vertical feedback has to be delineated from horizontal feedback (e.g. as in predator-prey relationships) that constitutes emergence in the natural sciences. A further aspect where the social constructivist interpretation differs from the emergence approach derived from the natural sciences concerns the direction and quantification of feedback. With respect to international relations, the feedback mechanism cannot easily be divided into positive and negative feedback. The social constructivist concept of emergence applied here restricts itself to qualitative feedback, because a fixed quantitative unit accounting for the precise impact of feedback is missing. In general, the feedback from international organizations to their constituencies is not quantitatively measurable. This is the case because unlike predator-prey relationships, where the relative size of the populations is the measurable unit that accounts for the alteration of positive and negative feedbacks, such a unit cannot be identified in general for the relationships between international organizations and their member states. For a conceptualization of emergence in the tradition of the natural sciences, see Beckenkamp (2006). 
environment in which states operate. States and international organizations would be part of the same social process, which alters or influences their respective identities and self-perceptions.

Once an international organization is created, there are different possibilities how the relationship between the organization and its members develops. It depends on this dynamic whether the organization turns out to be an emergent corporate actor. Three cases of constitutive interaction between nation-states and international organizations can be conceived of:

a) In the first case, the interests of the nation-states that are responsible for building international organizations are unaltered and still operative in subsequent periods. State interests are relatively constant, and the behavior of international organizations reflects this environment. This case is referred to by Haas \& Haas (1995: 260) as a long bygone time, where the bureaucrats of an organization simply "mirrored the interests, perceptions, and forces external to the IO”. However such a simplistic and instrumental view of international organizations is still embraced by two of the three mainstream theories of international relations. It is the standard case of rational choice institutionalism but also fits the neorealist approach of international organizations. For the latter theory, it has been shown that cooperation hardly emerges due to relative positionality considerations. Only from a defensive neorealist perspective, it is conceivable that international organizations are created to institutionalize a given situation of balance of power.

b) In the second case, the preferences and values of the member states of an organization have changed, while the organization remains static. Accordingly, structure and goals embodied in organizations reflect interests that have historically been operative but are no longer effective. ${ }^{56}$ This organizational inertia accounts for feedback from the organization to its constituencies. In the words of Haas/Haas (1995: 260), the "role-playing inside the IO can shape events". Therefore, this case goes beyond individualistic or reductionist interpretations of corporate actors in general and international organizations in particular.

It is based on the idea that the interests of member states change faster compared to the static and inertia exhibited by organizations and the administrative staff, socialized to perform specific roles. Organizations carry over former interests of their members into the future. In a way, this second case is about international organizations that confront states with their old self. However, this explanation is not fully satisfactory, because international organizations are not really autonomous corporate actors. They simply appear autonomous, since the interests of the states have changed and thus the organization has an impact on them. A further as-

56 This path-dependency is a core element of historic institutionalism and described by Krasner (1993) with respect to the Peace of Westphalia. He argues that the Treaty of Westphalia is not an example for the independent power of ideas, namely the idea of state sovereignty. Instead, interests and powers account for the creation of sovereign states, and the idea of sovereignty expressed in the Treaty of Westphalia was an ex post legitimation. Nevertheless, he admits that subsequently these ideas had an impact on politics and especially on the behavior of states. The ideas associated with sovereignty "have been used to codify existing practices rather than to initiate new forms of order” (Krasner 1993: 238). They have been useful as a defense against contesting principles such as papacy and international law. 
pect would be to find an explanation for the common intuition according to which international organizations exhibit exceptional inertia.

c) Ernst Haas gives an implicit explanation why international organizations are corporate actors in the sense of an emergent phenomenon:

“They [Organizations] reflect more than the initial convergence of actor demands because actor interests themselves may change in response to new knowledge; organizations may autonomously feed the process of change by the information and ideas they are able to mobilize" (Haas 1995: 57).

This third case is based on the assumption that international organizations are capable of learning and generating new knowledge or ideas. In the work of Haas/Haas, social learning is possible because institutions form a discourse-arena for scholars. Social scientists together with political actors consensually develop new policies. The social scientists are observers of the political process and are thereby detached from the object of study. Although their reality is socially constructed as well, there is less social pressure than in the policy field itself (Haas/Haas 2002: 586-588, Haas 2004: 587). The consensual knowledge of policy field specific epistemic communities fuels the learning process of international organizations. In order for knowledge successfully to "speak to power", it must have the three characteristics of "usable knowledge”: credibility, legitimacy, and saliency (Haas 2004: 573-576). The international organization is the arena that made this knowledge possible and the medium through which this new knowledge might cause repercussions. It has the power to alter the actors' interests and identities. Therefore, the international organization is created by nation-states, but through the knowledge it generates it causes feedback that has the potential power to change the interests of its constituencies. From a social constructivist perspective, this is exactly what emergence is about. 'Emergence' is the mechanism that simultaneously explains the constitution and the autonomy of corporate actors. Its basic logic is applied here to international organizations, but 'emergence' equally applies to the constitution of lower-order corporate actors.

In the following section, the knowledge-generating function of international organizations is explored in further detail and combined with Wendt's social theory. Drawing on recent social constructivist literature, it is argued that autonomous international organizations exhibit "productive power” (Barnett/Duvall 2005: 45-49), thus having “constitutive effects” (Barnett/Finnemore 2004: 29-34) on their members and environments that go beyond regulative governance forms.

\section{Knowledge generation and the productive power of discourses}

Although international organizations are not part of the social constructivist argument, made by Wendt, ${ }^{57}$ that agents and structures determine each other mutually and are not separable, they

57 Wendt's social theory is clearly state-centered, and there are hardly any references made to international organizations. Wendt's anthropomorphism of the state (Wendt 2004) has been subject to severe criticism. Especially its “under-sociological essence” (Guzzini/Leander 2001: 332) is considered unnecessary, although 
could be included in his theory by combining it with the approach by Haas/Haas (2002) of learning international organizations mentioned above. Wendt (1997: 59-62) acknowledges that states transfer sovereignty to collectives, but he maintains that states do not disappear or erode. What happens is an "internationalization of the state" (Wendt 1997: 61). This view of sovereignty transfer to the supranational level leaves room for a conceptualization of partly autonomous international organizations. ${ }^{58}$

Hence, international organizations are part of the international structure in which the states are embedded. Since the structure of the international system and states constitute each other mutually, international organizations 'make a difference' in the sense that they are more influential than reductionist explanations suggest. They affect the dominant culture by providing knowledge and framing discourses. The idea of an evolution towards a Kantian culture dominating the international system suggests a large (future) scope for international organizations. Moreover, the focus on the distribution of ideas as a major factor in constituting interests and identities is the key element in Wendt's social theory of international relations that enables a conceptualization of international organizations as (partly) autonomous actors. Thus, analogous to the relationship between society and persons, international organizations are created by state interaction, but at the same time they are able to change the basis of interaction: the identities of states (Simmons/Martin 2002: 198, Haas/Haas 2002). ${ }^{59}$ This is possible because organizations also respond to "normative and cultural forces that shape how organizations see the world and conceptualize their own missions" (Barnett/Finnemore 1999: 703). Put differently: There is feedback - from the level of the organization back to the identities of its constituencies - that is crucial because it constitutes the basis for the actor-quality of international organizations. In this respect, the autonomy of international organizations crucially depends on their power to alter the conditions of their own existence (state interests and perceptions) which depends on their capacities to generate knowledge.

it provides the basis for his application of symbolic interactionism to the international relations field (cf. Guzzini/Leander 2001: 332/333). However, Wendt does not argue that domestic politics is irrelevant regarding the formation of state interests. Indeed, he points out that he does "not claim that states are constructed primarily by international structures. Much of the construction is at the domestic level, as liberals have emphasized, and a complete theory of state identity needs to have a large domestic component. But these identities are made possible by and embedded in a systemic context” (Wendt 1999: 21). Resorting to a distinction made by Waltz (1979: 114-116), Wendt argues that domestic politics can be analytically separated from systemic politics, because the former is hierarchically ordered, whereas the latter is horizontally structured according to one type of anarchic culture (Wendt 1999: 10-15).

58 While the transfer of sovereignty from the nation states to the supranational level enables international organizations to produce knowledge, the downside of the autonomy granted to international organizations is the lack of democratic accountability. This issue is not addressed here, although its increasing salience is acknowledged: Scholars theorizing democracy traditionally dealt with ways and means to make state power accountable. Democracy at international level has not been an important issue in democratic and international relations theory, but will probably become more and more important as discussions about the democratic deficit of the Bretton Woods organizations indicate. The evolution from an anarchic structure of the international system towards a system of Kantian collective identity formation raises the question of accountability of international organizations and transnational cooperation in general.

59 This analogy is problematic in the sense that persons are not conceivable without society (Durkheim 1965: 190, Giddens 1979: 50), whereas states without international organizations clearly are. Therefore it seems obvious that states are causally prior to international organizations. However, the existence of states always involves relations among these states that constitute a structure of the international system. 
So far, it has been stressed that the autonomy of international organizations depends on their ability to generate knowledge. This automatically leads to the question how international organizations generate this knowledge. According to the constructivism of Barnett/Finnemore (2004), the autonomy and power of international organizations stem from their bureaucratic structure, which controls information and gives meaning to information. Through their often exclusive access to information, bureaucrats have the power to transform information into knowledge and thus influence outcomes. They often decide what kind of data is collected and how it is categorized (cf. Barnett/Finnemore 2004: 30). The policies and norms international organizations diffuse depend not just on international bureaucrats, but also on the epistemic communities surrounding international organizations as well as their internal organizational structure (cf. Finnemore/Sikkink 1998: 899). This suggests that international organizations are not just the agents of states, but they are powerful principals themselves because they establish international norms that are able to change state policies and structure. ${ }^{60}$ Finnemore (1993: 593) concludes that "states are more socially responsive entities than is recognized by traditional international relations theory", and thus social constructivism is better suited to explain the autonomous role of international organizations. In marked contrast to neorealist and rational choice approaches, the causality of the relationship between state actors and international organizations is not unidirectional, which implies that international organizations are neither state-operated instruments nor mere functional solutions to collective action problems. Instead, international organizations are seen as partly autonomous actors. ${ }^{61}$

As shown by social psychology, communication is very important for the development of the self. By the same token, interests and identities of states are shaped by discourses, which belong to the realm of international practice. Perhaps the most important aspect of interaction or practice is communication. Taking into account that social constructivism draws on social psychology, it does not surprise that discourses are the mainstay of social constructivist research. A Foucaultian and a Habermasian tradition can be distinguished (cf. Risse 2007: 136-139). According to Foucault, discourses sustain existing power structures because they exhibit the power to define and interpret problems and meanings. In contrast to this view, discourses or communication in the sense of Habermas are the place where rationality rules. In discursive processes, positions have to be backed by arguments. Thus, communicative processes allow dominant discourses to be contested by counter-discourses. This implies that although discourses do create structures of power through interpretation, these interpretations can change, and thereby it is also possible to alter the power structure. In this sense, knowledge production and discursive processes are de-

60 This conceptualization of international organizations as "teachers of norms" (Finnemore 1993) has been empirically underpinned by Finnemore (1993) concerning the active and decisive role of the UNESCO in the development of national science policy. Similarly, March/Olsen (1995), in the wider context of their theory of organizational behavior, argue that "institutions shape the definition of alternatives and influence the perception and construction of the reality within action takes place. Institutional capabilities and structures affect the flow of information, the kinds of search undertaken, and the interpretations made of the results" (March/Olsen 1995: 29).

61 Therefore, social constructivism differs from international political economy approaches (cf. Strange 1997), which perceive international organizations as "essentially system preserving", reinforcing the "legitimacy of market regimes" (Strange 1997: 171). 
scribed by Barnett/Duvall (2005: 55-57) as "productive power". ${ }^{62}$ This refers to the ability of discursive practices to impute meaning, alter perceptions and ultimately change behavior. This is done by establishing categories of classification or framing, for example classifying states as 'democratic' or 'civilized' (cf. Barnett/Duvall 2005: 56). A social policy example would be to distinguish between systemic and parametric pension reforms or sustainable and non-sustainable social security financing methods. International organizations, through their generation of knowledge, exert significant productive power.

The productive power of international organizations lies not in its regulative but in its constitutive effects. Regulation refers to changes in the incentive structure (e.g., policy-based lending) or the collection and publication of information in order to create public (peer) pressures concerning a specific behavior (e.g. UN monitoring activities). Constitution goes beyond regulation, in the sense that it seeks to create social reality through framing of problems and solutions. One example of such constitutive effects that the work of international organizations exhibits is the statistics on absolute poverty levels in Africa, which are interpreted and presented by UN organizations as a serious ‘developmental problem' or a ‘crisis'. Similarly, the World Bank derives the need for social security privatization from the evidence it constructs on a 'global demographic crisis'. International organizations yield constitutive and regulative effects through the creation of categories, the attachment of specific meanings to raw data, and through an articulation and diffusion of new norms and rules (cf. Barnett/Finnemore 2004: 29-34).

This relates to the more general topic of instruments of governance: Governance through knowledge is the softest of the instruments available to international organizations. Its productive power is diffuse. On the scale towards harsher instruments, it is followed first by incentives and then by command-and-control instruments (Verbote being generally relatively less restrictive, and Gebote more restrictive). Empirically, international organizations could be ranked on such a continuum ranging from soft to hard law/instruments. But is an international organization possessing 'hard instruments' more important or powerful? Not necessarily, because if power is conceived as the autonomous (emergent) power of international organizations, then 'soft instruments' turn out to ascribe more power to international organizations than 'hard instruments', which tend to be confined to international and not supranational control. Thus, 'power' is not to be measured in outcomes, because this would confound the power of the organization with the power of states that operate through international organizations. The genuine power and autonomy of an international organization depends on its potential to alter the interests and identities of its members. Then it is justified to speak of an international corporate actor. Future research should seek empirical support for this view. The question would be as follows: are there interna-

62 According to a typology by Barnett/Duvall (2005: 45-49), productive power is characterized by "constitution". This means that power is located in social relations constituting actors and their identities, thus drawing on the idea of co-determination as expressed by Wendt (see above). The second characteristic of productive power concerns the indirect way of its working, which is described as "diffuse". Thus, the effects of productive power are hard to detect because they operate in a mediated form with possibly unintended and/or longrun effects as opposed to direct causality (Barnett/Duvall 2005: 47-49). 
tional organizations that exhibit more autonomous power than other organizations that are commonly described as being much more powerful in terms of 'hard' governance instruments?

\section{Conclusion}

In this paper, the implicit and explicit conceptualizations found in the three major theories of international relations have been outlined and compared. It turns out that in a neorealist framework, international organizations can be explained; however, they exhibit no autonomy and cannot therefore be conceptualized as a corporate actor. Principally, the same applies to rational choice institutionalism, although limited autonomy is conceivable. Both theories are reductionist in the sense that they do not allow a corporate actor beyond the nation-state. International organizations are at best instruments of state interests. Solely social constructivist theories allow a conceptualization of international organizations as partly autonomous corporate actors. The reason for this conceptual openness lies in its ontology that includes ideational factors such as knowledge and ideas. The concept of emergence gives the core explanation for international organization autonomy: identities and interests of states and international organizations constitute each other mutually. This is specified by referring to the generation of new knowledge within international organizations as the key feature which accounts for feedbacks to the member-states of international organizations. This power of international organizations to alter perceptions and identities of their own 'founding fathers' makes them more than state instruments. International organizations thereby gain autonomy, which justifies conceiving of them as high-order corporate actors in international relations. 


\section{References}

Abbott, Kenneth W./Snidal, Duncan 1998: Why States Act through Formal International Organizations. In: Journal of Conflict Resolution 42 (1), 3-32.

Abrahamsson, Hans 2003: Understanding World Order and Structural Change. Poverty, Conflict and the Global Arena. Palgrave Macmillan: Houndmills.

Adler, Emanuel 2002: Constructivism and International Relations. In: Carlsnaes, Walter/Risse, Thomas/Simmons, Beth A. (eds.): Handbook of International Relations. Sage: London et al., 95-118.

Alchian, Armen A./Demsetz, Harold 1972: Production, Information Costs, and Economic Organization. In: American Economic Review 62 (5), 777-795.

Axelrod, Robert 1981: The Emergence of Cooperation among Egoists. In: American Political Science Review 75 (2), 306-318.

Axelrod, Robert 1984: The Evolution of Co-operation. Penguin: London et al.

Barnett, Michael/Duvall, Raymond 2005: Power in International Politics. In: International Organization 59 (1), 39-75.

Barnett, Michael/Finnemore, Martha 1999: The Politics, Power, and Pathologies of International Organizations. In: International Organization 53 (4), 699-732.

Barnett, Michael/Finnemore, Martha 2004: Rules for the World. International Organizations in Global Politics. Ithaca and London: Cornell UP.

Beckenkamp, Martin 2006: The herd moves? Emergence and self-organization in collective actors. Preprints of the Max Planck Institute for the Research on Collective Goods 14.

Berger, Peter L./Luckmann, Thomas 1991: The Social Construction of Reality. A Treatise in the Sociology of Knowledge. Penguin Books. London et al.

Bhaskar, Roy 1982: Emergence, Explanation, and Emancipation. In: Secord, Paul F. (ed.): Explaining Human Behaviour. Consciousness, Human Action and Social Structure. Beverly Hills et al.: Sage, 275-310.

Bhaskar, Roy 1998/1979: The Possibility of Naturalism. A Philosophical Critique of the Contemporary Human Sciences. Third Edition. London and New York: Routledge.

Bolton, Gary E./Ockenfels, Axel 2000: ERC: A Theory of Equity, Reciprocity, and Competition. In: American Economic Review 90 (1), 166-193.

Coase, R. H. 1937: The Nature of the Firm. In: Economica 4 (16), 386-405.

Dufwenberg, Martin/Kirchsteiger, Georg 2004: A Theory of Sequential Reciprocity. In: Games and Economic Behavior 47, 268-298.

Durkheim, Emile 1965: Regeln der soziologischen Methode. 2. Auflage. Neuwied und Berlin: Luchterhand.

Engel, Christoph 2006: Wettbewerb als sozial erwünschtes Dilemma. Preprints of the Max Planck Institute for Research on Collective Goods 12.

Falk, Armin/Fischbacher, Urs 2006: A Theory of Reciprocity. In: Games and Economic Behavior 54, 293-315. 
Fehr, Ernst/Schmidt, Klaus M. 1999: A Theory of Fairness, Competition, and Cooperation. In: Quarterly Journal of Economics 114 (3), 817-868.

Finnemore, Martha 1993: International Organizations as Teachers of Norms: The United Nations’ Educational, Scientific and Cultural Organization and Science Policy. In: International Organization 47 (4), 565-597.

Finnemore, Martha/Sikkink, Kathryn 1998: International Norm Dynamics and Political Change. In: International Organization 52 (4), 887-917.

Flam, Helena 1990: Corporate Actors: Definition, Genesis, and Interaction. MPIFG Discussion Paper 90/11.

Forde, Steven 1995: International Realism and the Science of Politics: Thucydides, Machiavelli, and Neorealism. In: International Studies Quarterly 39 (2), 141-160.

Foss, Nicolai J. 2000: The Theory of the Firm. An Introduction to Themes and Contributions. In: Foss, Nicolai J. (ed.): The Theory of the Firm. Critical Perspectives on Business and Management. Vol. 1. Routledge: London and New York, xv-lvi.

Frey, Bruno S. 1997: The public choice of international organizations. In: Mueller, Dennis C. (ed): Perspectives on public choice. A handbook. Cambridge, New York and Oakleigh: Cambridge UP, 106-123.

Giddens, Anthony 1979: Central Problems in Social Theory. Action, structure and contradiction in social analysis. London and Basingstoke: Macmillan.

Goldstein, Judith/Keohane, Robert O. 1993: Ideas and Foreign Policy: An Analytical Framework. In: Goldstein, Judith/Keohane, Robert O. (eds.): Ideas and Foreign Policy. Beliefs, Institutions and Political Change. Cornell University Press. New York, 3-30.

Gourevitch, Peter 1978: “The Second Image Reversed: The International Sources of Domestic Politics,” In: International Organization 32 (4), 881-912.

Gourevitch, Peter 2002: Domestic Politics and International Relations. In: Carlsnaes, Walter/Risse, Thomas/Simmons, Beth A. (eds.) Handbook of International Relations. Sage: London et al., 309-328.

Grieco, Joseph M. 1988: Anarchy and the Limits of Cooperation: A Realist Critique of the Newest Liberal Institutionalism. In: International Organization 42 (3), 485-507.

Grieco, Joseph/Powell, Robert/Snidal, Duncan 1993: The relative-gains problem for international cooperation. In: American Political Science Review 87 (3), 729-743.

Guzzini, Stefano/Leander, Anna 2001: A Social Theory for International Relations: An Appraisal of Alexander Wendt's Theoretical and Disciplinary Synthesis. In: Journal of International Relations and Development 4 (4), 316-338.

Haas, Ernst B. 1995: Words can hurt you; or, who said what to whom about regimes. In: Krasner, Stephen D. (ed.): International Regimes. Cornell UP: Ithaca and London, 23-59.

Haas, Peter M. \& Haas, Ernst B. 1995: Learning to Learn: Improving International Governance. In: Global Governance 1, 255-285.

Haas, Peter M. \& Haas, Ernst B. 2002: Pragmatic Constructivism and the Study of International Institutions. In: Millennium 31 (3), 573-601. 
Haas, Peter M. 2004: When does power listen to truth? A constructivist approach to the policy process. In: Journal of European Public Policy 11 (4), 569-592.

Hansen, Lene 1996: International Institutions in International Relations Theory. In: de Wilde, Jaap/Wiberg, Håkan (eds.): Organized Anarchy in Europe. The role of states and intergovernmental organizations. Tauris: London and New York, 23-38.

Hasenclever, Andreas/ Mayer, Peter/ Rittberger, Volker 1997: Theories of International Regimes. Cambridge UP.

International Labour Organization 2005: Structure of the ILO. Factsheet 1.2. URL: http://www.ilo.org/public/english/region/eurpro/london/download/fp1_2.pdf (accessed on 17th of October 2005).

Keohane, Robert O. 2002: International relations and international law: two optics. In: Keohane, Robert O. (ed.): Power and Governance in a Partially Globalized World. Routledge: London and New York, 117-131.

Keohane, Robert O. 2005: After Hegemony. Cooperation and Discord in the World Political Economy. Princeton UP: Princeton and Oxford.

Koremenos, Barbara/Lipson, Charles/Snidal, Duncan 2001: The Rational Design of International Institutions. In: International Organization 55 (4), 761-799.

Krasner, Stephen D. 1993: Westphalia and All That. In: Goldstein, Judith/Keohane, Robert O. (eds.): Ideas and Foreign Policy. Beliefs, Institutions and Political Change. Cornell University Press. New York, 235-264.

Krasner, Stephen D. 1995: Structural causes and regime consequences: regimes as intervening variables. In: Krasner, Stephen D. (ed.): International Regimes. Cornell UP: Ithaca and London, 1-21.

Kratochwil, Friedrich/Ruggie, John Gerard 1986: International Organization: A State of the Art on an Art of the State. In: International Organization 40 (4), 753-775.

Kreps, David M. et al. 1982: Rational Cooperation in the Finitely Repeated Prisoners' Dilemma. In: Journal of Economic Theory 27 (2), 245-252.

March, James G./Olsen, Johan P. 1995: Democratic Governance. New York: The Free Press.

Martin, Lisa L. 1999: The Political Economy of International Cooperation. In: Kaul, Inge/Grunberg, Isabelle/Stern, Marc A. (eds.): Global Public Goods. International Cooperation in the $21^{\text {st }}$ Century. New York and Oxford, Oxford UP, 51-64.

Mead, George Herbert 1964: The Problem of Society - How We Become Selves. In: Strauss, Anselm (ed.): George Herbert Mead On Social Psychology. Selected papers. Revised Edition. University of Chicago Press, Chicago and London.

Mearsheimer, John J. 1994/1995: The False Promise of International Institutions. In: International Security 19 (3), 5-49.

Moravcsik, Andrew 1997: Taking Preferences Seriously: A Liberal Theory of International Politics. In: International Organization 51 (4), 513-553. 
Morgenthau, Hans J. 1953: Political limitations of the United Nations. In: Lipsky, Georg A. (ed): Law and Politics in the World Community. Essays on Hans Kelsen's Pure Theory and Related Problems in International Law, Berkeley/Los Angeles: University of California Press, 143-152.

Ness, Gayl D./Brechin, Steven R. 1988: Bridging the Gap: International Organizations as Organizations. In: International Organization 42 (2), 245-273.

North, Douglass C. 1990: Institutions, Institutional Change, and Economic Performance. Cambridge ; New York, Cambridge UP.

Olson, Mancur 1968: Die Logik des kollektiven Handelns. Kollektivgüter und die Theorie der Gruppen. Tübingen, Mohr.

Onuf, Nicholas Greenwood 1989: World of Our Making: Rules and Rule in Social Theory and International Relations. Columbia, University of South Carolina Press.

Peters, Anne 2006: Völkerrecht: Allgemeiner Teil. Zürich et al., Schulthess.

Powell, Robert 1994: Anarchy in International Relations Theory: The Neorealist-Neoliberal Debate. In: International Organization 48 (2), 313-44.

Putnam, Robert D. 1988: Diplomacy and domestic politics: the logic of two-level games. In: International Organization 42 (3), 427-460.

Risse, Thomas 2007: Social Constructivism Meets Globalization. In: Held, David/McGrew, Anthony (eds): Globalization Theory. Approaches and Controversies. Polity Press. Cambridge and Malden, 126-147.

Selten, Reinhard 1978: The Chain Store Paradox. In: Theory and Decision 9 (2), 127-159.

Selten, Reinhard/Stoecker, Rolf 1986: End Behavior in Finite Prisoner's Dilemma Supergames. A Learning Theory Approach. In: Journal of Economic Behavior \& Organization 7 (1), 47 70 .

Shanks, Cheryl/Jacobson, Harold K./Kaplan, Jeffrey H. 1996: Inertia and Change in the Constellation of International Governmental Organizations, 1981-1992. In: International Organization 50 (4), 593-627.

Simmons, Beth A./Martin, Lisa L. 2002: International Organizations and Institutions. In: Carlsnaes, Walter/Risse, Thomas/Simmons, Beth A. (eds.) Handbook of International Relations. Sage: London et al., 192-211.

Stein, Arthur A. 1995: Coordination and collaboration: regimes in an anarchic world. In: Krasner, Stephen D. (ed.): International Regimes. Cornell UP: Ithaca and London, 115-140.

Strange, Susan 1997: The Retreat of the State. The Diffusion of Power in the World Economy. Cambridge UP. Cambridge, New York and Melbourne.

Ulbert, Cornelia 2005: Konstruktivistische Analysen der internationalen Politik. Theoretische Ansätze und methodische Herangehensweisen. In: Ulbert, Cornelia/Weller, Christoph (eds.): Konstruktivistische Analysen der internationalen Politik. Wiesbaden: VS-Verlag, 934.

Vaubel, Roland 2006: Principal-agent problems in international organizations. In: Review of International Organizations 1 (2), 125-138. 
Wade, Robert Hunter 2002: US hegemony and the World Bank: the fight over people and ideas. In: Review of International Political Economy 9 (2), 215-243.

Waltz, Kenneth N. 1979: Theory of International Politics. McGraw-Hill: London et al.

Waltz, Kenneth N. 2000: Structural Realism after the Cold War. In: International Security 25 (1), 5-41.

Weller, Christoph 2005: Perspektiven eines reflexiven Konstruktivismus für die internationalen Beziehungen. In: Ulbert, Cornelia/Weller, Christoph (eds.): Konstruktivistische Analysen der internationalen Politik. Wiesbaden: VS-Verlag, 35-64.

Wendt, Alexander 1987: The Agent-Structure Problem in International Relations Theory. In: International Organization 41 (3), 335-370.

Wendt, Alexander 1992: Anarchy is What States Make of It: The Social Construction of Power Politics. In: International Organization 46 (2), 391-425.

Wendt, Alexander 1994: Collective Identity Formation and the International State. In: American Political Science Review 88 (2), 384-396.

Wendt, Alexander 1997: Identity and Structural Change in International Politics. In: Lapid, Yosef/Kratochwil, Friedrich (eds): The Return of Culture and Identity in IR Theory. Lynne Rienner Publishers. Boulder and London, 47-64.

Wendt, Alexander 1999: Social Theory of International Politics. Cambridge UP: Cambridge.

Wendt, Alexander 2004: The state as person in international theory. In: Review of International Studies 30, 289-316.

Woods, Ngaire 1995: Economic Ideas and International Relations: Beyond Rational Neglect. In: International Studies Quarterly 39 (2), 161-180. 